\title{
The Effect of Collagen Coating on Surface Biocompatibility of the Titanium Alloys
}

\author{
Jianping Gao* \\ National Key Laboratory of \\ Biochemical Engineering, Institute of \\ Process Engineering, Chinese \\ Academy of Sciences, Beijing 100190, \\ China;School of Chemical and \\ Engineering, University of Chinese \\ Academy of Sciences, Beijing, 100049, \\ China \\ jpgao@ipe.ac.cn

\section{Yang Zhang} \\ National Key Laboratory of \\ Biochemical Engineering, Institute of \\ Process Engineering, Chinese \\ Academy of Sciences, Beijing 100190, \\ China \\ zhangyang21@ipe.ac.cn \\ Yingjun Kong \\ National Key Laboratory of \\ Biochemical Engineering, Institute of \\ Process Engineering, Chinese \\ Academy of Sciences, Beijing 100190, \\ China;School of Chemical and \\ Engineering, University of Chinese \\ Academy of Sciences, Beijing, 100049, \\ China \\ yjkong@ipe.ac.cn
}

\section{Saina Li}

National Key Laboratory of

Biochemical Engineering, Institute of

Process Engineering, Chinese

Academy of Sciences, Beijing 100190,

China;School of Chemical and

Engineering, University of Chinese

Academy of Sciences, Beijing, 100049, China

\section{Yi Chen}

Beijing Biosis Healing Biological

Technology Co., L, Beijing, 100026,

China

\section{Xi Luo}

National Key Laboratory of

Biochemical Engineering, Institute of

Process Engineering, Chinese

Academy of Sciences, Beijing 100190,

China;School of Chemical and

Engineering, University of Chinese

Academy of Sciences, Beijing, 100049,

China

xluo@ipe.ac.cn

\section{Lun Zhang}

National Key Laboratory of

Biochemical Engineering, Institute of

Process Engineering, Chinese

Academy of Sciences, Beijing 100190,

China;School of Chemical and

Engineering, University of Chinese

Academy of Sciences, Beijing, 100049, China

\section{Fangyu Xing}

National Key Laboratory of

Biochemical Engineering, Institute of

Process Engineering, Chinese

Academy of Sciences, Beijing 100190,

China

xingfangyu21@ipe.ac.cn

\section{Guifeng Zhang}

National Key Laboratory of

Biochemical Engineering, Institute of

Process Engineering, Chinese

Academy of Sciences, Beijing 100190,

China;School of Chemical and

Engineering, University of Chinese

Academy of Sciences, Beijing, 100049,

China

gfzhang@ipe.ac.cn

\begin{abstract}
Titanium alloys coated with collagen have been widely used to improve their biocompatibility. In this study, the titanium alloys were coated with type I collagen (Col I) and type II collagen (Col II), respectively. The coating amount was quantified with HPLC/MS Their biocompatibility was evaluated and the effects of collagen types on cell differentiation were compared by cellular proteins identification and quantification. The quantity of $\mathrm{Col} \mathrm{I}$ and $\mathrm{Col}$ II coated on titanium alloy were $0.813 \pm 0.015 \mathrm{mg}$ and $0.774 \pm 0.013$ $\mathrm{mg}$, respectively. Mouse Col I and fibronectin were abundantly expressed within Col I group. The most abundant proteins in Col II group were osteopontin and prelamin-A/C. In conclusion, the
\end{abstract}

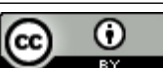

This work is licensed under a Creative Commons Attribution International 4.0 License.

BECB 2021, August 13-15, 2021, Nanchang, China

(C) 2021 Copyright held by the owner/author(s).

ACM ISBN 978-1-4503-8411-7/21/08

https://doi.org/10.1145/3502060.3502144 collagen coating could improve the biocompatibility of titanium alloy materials, and different types of collagen could induce cell to express proteins with various functions.

\section{KEYWORDS}

Titanium alloy, collagen coating, surface biocompatibility, cell differentiation, HPLC/MS

\section{ACM Reference Format:}

Jianping Gao*, Saina Li, Lun Zhang, Yang Zhang, Yi Chen, Fangyu Xing, Yingjun Kong, Xi Luo, and Guifeng Zhang. 2021. The Effect of Collagen Coating on Surface Biocompatibility of the Titanium Alloys. In 2021 International Symposium on Biomedical Engineering and Computational Biology (BECB 2021), August 13-15, 2021, Nanchang, China. ACM, New York, NY, USA, 7 pages. https://doi.org/10.1145/3502060.3502144

\section{INTRODUCTION}

Titanium alloys are one kind of natural superplastic materials and have been widely used for replacing hard tissues, such as the bone, teeth and orthopedic implants due to their superior physical, mechanical and biological properties [1-3]. Titanium alloys are far 
superior to other metals or alloys in resistance to corrosion. They have light weight and superior tribological properties, and have become an important candidate in cardiovascular, orthopaedic and dental application [4-5]. The native titanium alloy surfaces are covered by oxide films which compromise their biological propertie [6]. Surface modification is the effective mean to change the alloying surface properties [7-8]. In order to improve the bioactivity and biocompatibility of the titanium alloy surfaces, the physical, chemical, biological and physicochemical methods were investigated [8]. Biochemical approach could result the increased surface features, however, most biomolecules had no affinity to the titanium alloys [9-12]. Coupling agents are required to bind with titanium alloy surfaces and biomolecules. Silanes, carboxylates and phosphates are usually used for this purpose [13-15]. As one of the most widely used crosslinkers, silane can provide stable covalent linkage between titanium alloy surfaces and proteins or other biopolymers [15-19].

The proteins, such as collagen, fibronectin, laminin, RGD peptide etc, coupled on the titanium alloy surfaces are the main determinant of the cytocompatibility, and they play an important role in hard tissue repair [20-22]. Collagen is the main component of the extracellular matrix. Due to its low antigenicity, good biocompatibility, biodegradability and non-toxicity, it has been widely used in tissue engineering [23-25]. It can induce cellular processes such as signaling, differentiation, migration, and apoptosis [26]. The arginine-glycine-aspartate (RGD) amino acid sequence in collagen can promote cell growth, attachment, and interact with integrin [27]. Type I collagen ( $\mathrm{Col} \mathrm{I}$ ) is widely present in bone, skin, tendon, ligament and so on. Type II collagen (Col II) is present in cartilage and vitreous humor [28]. Col I or Col II products are used for bone grafting and bone filling [29]. Col I has been exploited to enhance osteoblast adhesion and differentiation in vitro, and in vivo osseointegration of titanium alloys [30-32]. Nagai reported that Ti6Al4V alloy surfaces coated with Col I could promote fibroblast adhesion [33]. Kado proved that Col I coated titanium surfaces improved the adhesion and spreading of human periodontal ligament cells significantly [34]. Col II is more beneficial to chondrocyte phenotype formation and structure maintenance than $\mathrm{Col}$ I [35-38]. However, the difference comparison of $\mathrm{Col}$ I and $\mathrm{Col}$ II coated titanium alloys on biocompatibility and cell differentiation has not been studied thus far.

In this study, we coated Col I and Col II on titanium alloys using $\mathrm{KH}-550$ as a mediator for crosslinking. The amount of Col I and Col II coated on the titanium alloys was quantified using HPLC/MS. The biocompatibilities of these two materials were evaluated by culturing mouse pre-osteoblasts. Effects of Col I and Col II on cell differentiation were compared by cell protein recognition and quantification with HPLC-MS.

\section{MATERIALS AND METHODS}

\subsection{Chemicals and Materials}

Titanium alloys were provided by Peking University Dental Hospital. KH550 was provided by Sinopharm Group. Trypsin (sequence grade) was purchased from Promega (Madison, WI, USA). Type I and II collagens were purchased from Hebei Collatech Co Ltd.

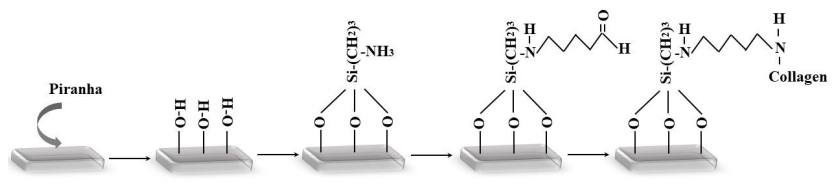

Figure 1: The process of collagen coating on the titanium alloys.

Cell line: Mouse embryonic osteoblast precursor cells (MC-3T3E1) were purchased from Cell Resource Center, Peking Union Medical College of China. $\alpha$-MEM culture medium was purchased from Thermo Fisher (San Jose, CA, USA). Glucose oxidase kit was purchased from Shanghai rsbio biopharmaceutical Co Ltd (Shanghai, China). MinuteTM animal cell total protein extraction kit was purchased from Invent Biotechnologies Inc (Taiwan, China). All other chemicals were commercial products of analytical grade.In a Word 2010 document, insert a picture.

\subsection{Chemicals and Materials}

2.2.1 Surface activation of titanium alloys. The titanium alloys $(\Phi 10 \mathrm{~cm})$ were washed with acetone, ethanol and ultra-pure water for $10 \mathrm{~min}$, respectively. They were dried, immersed in the Piranha solution, incubated at $90^{\circ} \mathrm{C}$ for $2 \mathrm{~h}$ and dried at $150{ }^{\circ} \mathrm{C}$ for $4 \mathrm{~h}$. Then they were put in $5 \% \mathrm{KH}-550$ toluene solution and incubated for 1 h. After that, the titanium alloys were immersed in toluene and ultrasonic cleaned for $10 \mathrm{~min}$. Finally, they were dried in the fume hood.

2.2.2 Glutaraldehyde coupling. After surface activated, the titanium alloys were immersed in $2.5 \%$ glutaraldehyde which contained $0.01 \%$ sodium borohydride at $40^{\circ} \mathrm{C}$ for $3 \mathrm{~h}$. Then they were washed with deionized water for five times, and each time was for $10 \mathrm{~min}$. At last, they were dried at room temperature for $2 \mathrm{~h}$.

2.2.3 Collagen coating. Bovine Col I was dissolved in $0.01 \mathrm{M}$ sodium acetate buffer ( $\mathrm{pH}$ 8.0). The surface-activated titanium alloys were placed in Col I solutions and reacted for $24 \mathrm{~h}$. Then they were washed by deionized water and placed in lysine solution (10 $\mathrm{mg} / \mathrm{mL}$ ) for $2 \mathrm{~h}$. Then the titanium alloys were washed again by deionized water, dried and stored at $4{ }^{\circ} \mathrm{C}$. The coating process of Col II was same as above. The process was shown in figure 1 .

\subsection{Characterization of modified Titanium alloys}

2.3.1 Analysis of surface element. X-ray photoelectron spectroscopy (XPS) spectrometer (ESCALAB 250Xi, Thermo Fisher Scientific, USA) was used to analyze the elementary of the modified titanium alloys. The samples were performed by XPS using an $\mathrm{Al} / \mathrm{K}$ $\left(\mathrm{h} \frac{1}{4} 1486.6 \mathrm{eV}\right)$ anode mono-X-ray source at power of $225 \mathrm{~W}$ with emission current $15 \mathrm{~mA}$ and operating voltage $15 \mathrm{kV}$. The XPS bonding energy (BE) values were charge corrected with respect to those of adventitious carbon at $284.8 \mathrm{eV}$. The minimum energy resolution is $0.48 \mathrm{eV}(\mathrm{Ag} 3 \mathrm{~d} 5 / 2)$. The diameter of XPS analysis region is $15 \mu \mathrm{m}$. The data are analyzed by Avantage data system software. The spectra of C1s, N1s, O1s and Si2p signals were collected. The concentrations of the elements were calculated by the peak areas. 
2.3.2 Protein quantification. The titanium alloys coated with collagen were placed in ammonium bicarbonate solution $(0.05 \mathrm{M}, \mathrm{pH}$ 8.0) and incubated at $60{ }^{\circ} \mathrm{C}$ for $30 \mathrm{~min}$. Then they were cooled to room temperature, mixed with $20 \mu \mathrm{g}$ trypsin, and incubated at $37^{\circ} \mathrm{C}$ for $18 \mathrm{~h}$. The supernatant was freeze-dried and resolved with $100 \mu \mathrm{f}$ ammonium bicarbonate solution $(0.05 \mathrm{M}, \mathrm{pH}$ 8.0). Then the samples were centrifuged for $10 \mathrm{~min}\left(4^{\circ} \mathrm{C}, 10,000 \mathrm{~g}\right)$, and supernatants were collected for analysis [28].

\subsection{Cell experiment}

2.4.1 Mouse pre-osteoblast cell culture. The titanium alloys were divided into three groups. The blank group was the titanium alloys only treated with Piranha solution. The Col I and Col II groups were the titanium alloys coated with $\mathrm{Col}$ I and Col II, respectively. All of the titanium alloys were cut into small pieces $(1 \times 1 \mathrm{~cm})$ and washed with $75 \%$ ethanol, irradiated with UV for $30 \mathrm{~min}$, then placed into the 24-well plate. The mouse pre-osteoblast cells at the logarithmic growth phase were digested with $0.25 \%$ trypsin and counted. The cell suspensions $(1 \times 105 / \mathrm{mL})$ were added into the well and the plate was incubated in 5\% CO2 saturated humidity incubator at 37 ${ }^{\circ} \mathrm{C}$. The DMEM/High Glucose was replaced every day.

2.4.2 Cell attachment status. After cell culture for $24 \mathrm{~h}, 3$ pieces titanium alloys of each group were taken and washed with phosphate buffer for 3 times. They were fixed with $2.5 \%$ glutaraldehyde for $1 \mathrm{~h}$ and washed with phosphate buffer for 3 times. Then they were dehydrated with gradual ethanol, dried with $\mathrm{CO} 2$ critical point and sprayed with gold. Scanning electron microscope (JSM 6700F, JEOL, Japan) was used to observe the state of cell adhesion on the surface of the material.

2.4.3 Cell counting. Three titanium alloys per group per day were used for cell counting. The lysis buffer (Reagent A100, Chemometec, Danmark) was used to elute the cells which attached onto the titanium alloys. In order to allow the nuclei to be stained by trypan blue, the lysis buffer was used to permeate the plasma membrane. Furthermore, cell clusters were disaggregated with the lysis buffer Then, cell nucleus was counted with a blood counting chamber.

\subsection{Protein mapping using HPLC-MS}

2.5.1 Tryptic digestion. After cultured for 3 days on the titanium alloys, the mouse pre-osteoblast cells were digested with $0.25 \%$ trypsin and washed by phosphate buffer for 3 times to remove the culture media. The cell protein was extracted by cell total protein extraction kit. The cellular protein solution was replaced by ammonium bicarbonate solution $(0.05 \mathrm{M}, \mathrm{pH} 8.0)$. The concentration of cellular protein was determined by BCA protein assay kit (Thermo, USA). Then the protein concentration was adjusted to $1 \mathrm{mg} / \mathrm{mL}$ with ammonium bicarbonate solution (0.05 M, pH 8.0). Dithiothreitol was added to the protein solution with a final concentration of $10 \mathrm{mM}$. The mixed solution was incubated at $37^{\circ} \mathrm{C}$ for $1 \mathrm{~h}$. When the samples were cooled to room temperature, the iodoacetamide was added to the solution to a final concentration of $55 \mathrm{mM}$. The mixtures were incubated at room temperature for $30 \mathrm{~min}$. Each sample was mixed with $20 \mu \mathrm{g}$ trypsin and incubated at $37^{\circ} \mathrm{C}$ for $18 \mathrm{~h}$. The digested solution was dried with a vacuum centrifuge. Then it was redissolved with $0.1 \%$ formic acid and centrifuged at
$10,000 \times \mathrm{g}$ for $10 \mathrm{~min}$. The supernatant was collected for HPLC-MS analysis.

2.5.2 HPLC-MS analysis. A C18 column $(75 \mu \mathrm{m} \times 15 \mathrm{~cm}, 3 \mu \mathrm{m}$, Dr. Maisch $\mathrm{GmbH}$ ) was used for peptide separation with an EASY-nLC 1000. Solvent A with water-FA (100:0.1, v/v) and solvent B with acetonitrile -FA (100:0.1, v/v) were used for the analysis. A gradient of elution program was as following: $0-5 \mathrm{~min}, 3 \%-8 \% \mathrm{~B}$; $5-45 \mathrm{~min}, 8 \%$ $20 \%$ B; 45-55min, 20\%-35\% B; 55-58min, 35\%-80\% B; 58-60min, $80 \%$ B. Flow rate: $400 \mathrm{~nL} / \mathrm{min}$. Online peptide identification was performed on an Orbitrap Fusion mass spectrometer (Orbitrap Fusion Tribrid, Thermo Fisher, San Jose, CA, USA), with a Nanospray Flex ion source. The MS scan range was $\mathrm{m} / \mathrm{z} 300-1800$ with a resolution setting of 120,000 , followed by Orbitrap HCD-MS/MS. The MS2 spectra resolution was 30,000 .

2.5.3 Protein mapping. MS/MS data was processed using Mascot Daemon (v.2.5.1, 2014, Matrix Science, Boston, USA). Bovine Col I and Col II database were used for bovine collagen marker peptide identification. Tandem mass spectra were used for collagen quantification. And mouse pre-osteoblasts databases were used for protein difference analysis. Two missing cleavages were allowed for trypsin cleavage. The mass error was set to $10 \mathrm{ppm}$ and $0.02 \mathrm{Da}$ for precursor and fragment ions, respectively.

\section{RESULTS}

\subsection{Element Analysis of KH550 modified titanium alloy}

To explore the modification process of titanium alloy surface, the XPS was used to detect all elements except for hydrogen and helium. The surface element composition of the samples before and after modification with KH550 was analyzed. The spectra were shown in figure 2. The surface atomic compositions and the ratio of $\mathrm{Ti}, \mathrm{Al}$, $\mathrm{V}, \mathrm{N}, \mathrm{O}, \mathrm{Si}, \mathrm{C}$ on the blank and modified titanium alloys were listed in Table 1. The binding energy that N1s signal peak appeared in the XPS spectrum of the titanium alloys modified with KH-550 was $399.4 \mathrm{eV}$. It corresponded to the binding energy of N1s in -NH2, and the results indicated that the titanium alloy surface was modified with aminosilane. The modified $\mathrm{C} 1 \mathrm{~s}$ signal peak appeared at the binding energy of $284.8 \mathrm{eV}$, which corresponded to the $\mathrm{C}-\mathrm{C}$ bond in $\mathrm{KH}-550$. It indicated that the modified $\mathrm{KH}-550$ was successfully coupled to the surface of the titanium alloys. The Si2p signal peak appeared at $102.2 \mathrm{eV}$, indicating that $\mathrm{Si}-\mathrm{O}$ bonds were formed between $\mathrm{Si}-\mathrm{OH}$ and $\mathrm{KH}-550$. There was $0.81 \% \mathrm{~N}$ on the surface of unmodified titanium alloys. It may be the non-specific adsorption of N2 in the air.

\subsection{Analysis of collagen content on titanium alloy surface}

Standard Col I and Col II were digested by trypsin and analyzed with HPLC-MS. The enzymatic peptide information was searched with Mascot software against the bovine Col I and Col II database. GFSGLDGAK and GEAGAQGPMGPAGPAGAR were confirmed as the marker peptides of Col I and Col II, respectively. And the MS/MS quantitative ions were $\mathrm{m} / \mathrm{z} 417.03$ and 980.87 , respectively (Figure 3). GLAGMA was selected as the internal standard. The 

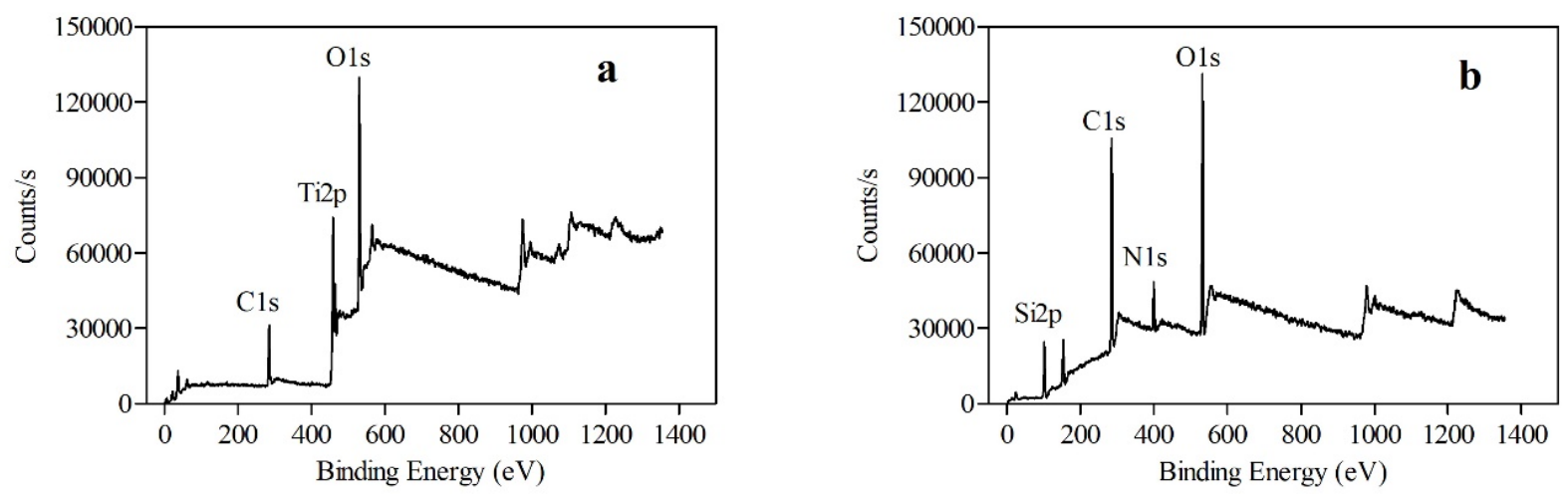

Figure 2: The XPS scan spectra of titanium alloys before (a) and after (b) modified by KH550.

Table 1: The surface elementary composition of the titanium alloys.

\begin{tabular}{lllllllll}
\hline & $\mathrm{Ti} / \%$ & $\mathrm{Al} / \%$ & $\mathrm{~V} / \%$ & $\mathrm{~N} / \%$ & $\mathrm{O} / \%$ & $\mathrm{Si} / \%$ & $\mathrm{C} / \%$ \\
\hline Bare & 29.7 & 3.47 & 0.42 & 0.81 & 64.53 & 1.06 & 28.65 \\
KH550 & 0.65 & 0 & 0 & 8.25 & 23.09 & 12.92 & 55.08 \\
\hline
\end{tabular}

concentration of marker peptide was the abscissa. The ratio of internal standard to marker peptide peak area was the ordinate. The linear regression equations were plotted: $A=0.615+0.018 \times C$, $\mathrm{R} 2=0.997$ (GFSGLDGAK) and $\mathrm{A}=-0.924+18.205 \times \mathrm{C}, \mathrm{R} 2=0.998$ (GEAGAQGPMGPAGPAGAR). The amount of Col I and Col II coated on the titanium alloys were $0.813 \pm 0.015 \mathrm{mg}$ and $0.774 \pm 0.013 \mathrm{mg}$, respectively.

\subsection{Cell attachment morphology}

SEM scan spectra of mouse pre-osteoblast cells cultured on three groups of titanium alloys for $24 \mathrm{~h}$ were shown in figure 4 . It indicated that the cells could attach and grow normally on the three groups of titanium alloys. The cell extension area on the surface of the blank group was small and most of the area formed a bulge to appear as strip-shaped, and the flat or polygonal cells were less, also were the pseudopodias of the cell. While the cells attached to the surface of Col I and Col II groups had a larger extension area, most were flat or polygonal, and the pseudopodia of cells were more than the blank group.

\subsection{Cell counting}

Nucleus counting was used to evaluate the proliferation of mouse pre-osteoblast cells growing on titanium alloys after 1,2 and 3 days (figure 5). It was found that cells cultured within Col I group was the most abundant. The number of cells in the blank group was the least. From the process of the cell proliferation, the proliferation rate of Col I group was the fastest, and that of the blank group was the slowest. The result showed that titanium alloys coated with Col I and Col II could promote the proliferation of mouse pre-osteoblast cells.

\subsection{Cell protein expression}

After cultured for 3 days, three groups of mouse pre-osteoblasts protein were digested and analyzed by HPLC-MS. Using all mouse pre-osteoblasts total protein as a database, three groups of enzymatic peptide information were searched with Mascot software. We found that there were 6 kinds of protein with significant differences among the three groups. Firstly, we identified the marker peptides of the 6 proteins. Then the marker peptides were synthesized, and the amount of proteins was quantified with the content of marker peptides (figure 6).

The peptide DGEAGAQGAPGPAGPAGER was identified in $\alpha 1$ chain of mouse Col I, but not presented in bovine Col I and other proteins. It was used as the marker peptide to quantify the mouse Col I in the cells. We found that the mouse Col I was abundantly expressed in the Col I group, and its relative content in Col I group was $18.9 \%$. The marker peptide of fibronectin was CDPIDQCQDSETR. The relative content of fibronectin was $23.0 \%$ in Col I group. These two proteins took the majority in Col I group. Other proteins were quantified with the same method. The marker peptides of osteopontin and prelamin-A/C were ESQESADQSDVIDSQASSK and EAAISTAISEK, respectively. Their contents in Col II group were higher than the blank and Col I group, which were $20.0 \%$ and $21.3 \%$, respectively. The marker peptide of alkaline phosphatase was QQAQETIK, whose content were $18.1 \%$ and $17.1 \%$ in the blank group and Col II group, and higher than Col I group. The content of nidogen-2 was $23.9 \%$ in the blank group, which was higher than the other groups.

\section{DISCUSSION}

In recent years, titanium alloys have been widely used as biomaterials in dental implants and artificial bone implants. Previous study 

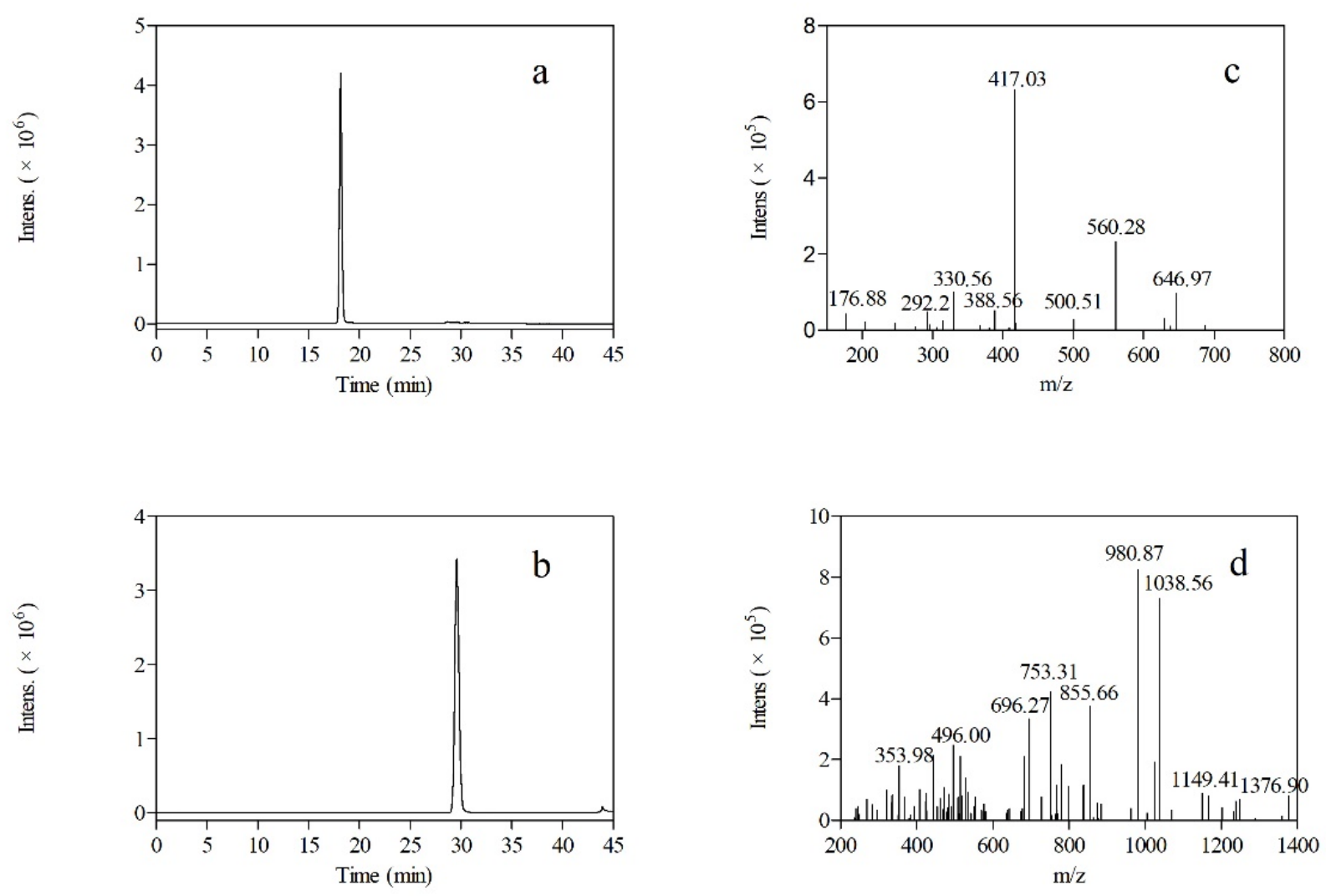

Figure 3: MS/MS extracted ion chromatograms of (a) GFSGLDGAK (a1(I)) and (b) GEAGAQGPMGPAGPAGAR (a1(II)) collagen peptides and their MS/MS spectras.
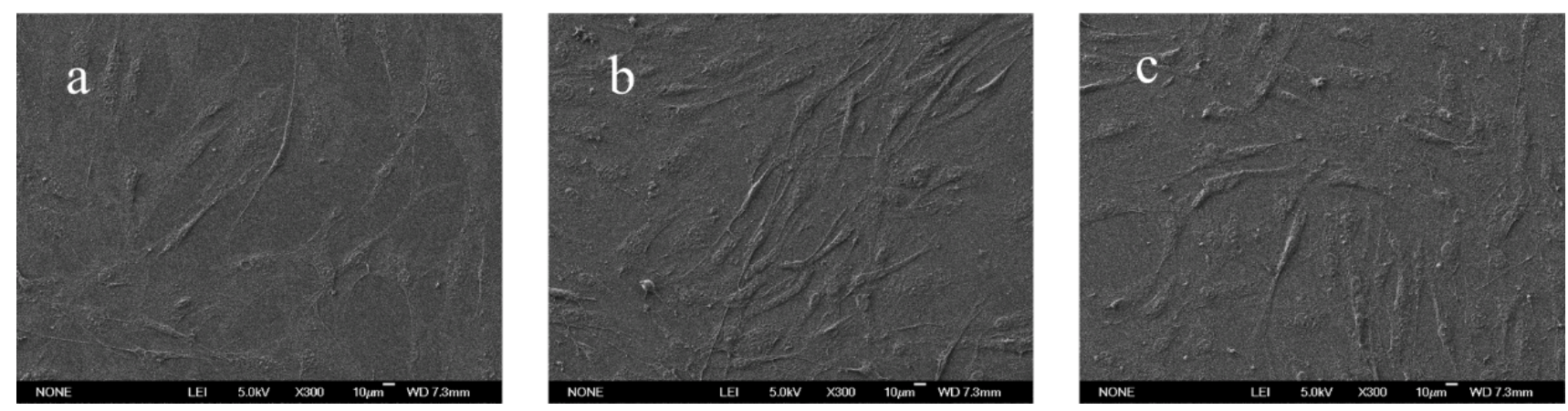

Figure 4: SEM scan spectra of blank group (A), Col I group (B) and Col II group (C) with the magnification 300.

has reported that $\mathrm{Col}$ I coated on the titanium alloys could promote cell adhesion [3]. No publications have reported the coating of Col II on titanium alloys. In this report, we coated Col I and Col II on titanium alloys and compared the differences in biocompatibility and cell differentiation between them.
Titanium alloys were modified with KH550. The element composition of the titanium alloys surfaces was analyzed by XPS. As shown in figure 1, the N1s peak at $399.4 \mathrm{eV}$ in Figure 1 (b) belonged to amidogen. The $\mathrm{C} 1 \mathrm{~s}$ peak at $284.8 \mathrm{eV}$ belonged to $\mathrm{C}-\mathrm{C}(284.6 \mathrm{eV})$ in $\mathrm{KH} 550$. It indicated that $\mathrm{KH}-550$ was successfully cultured onto 


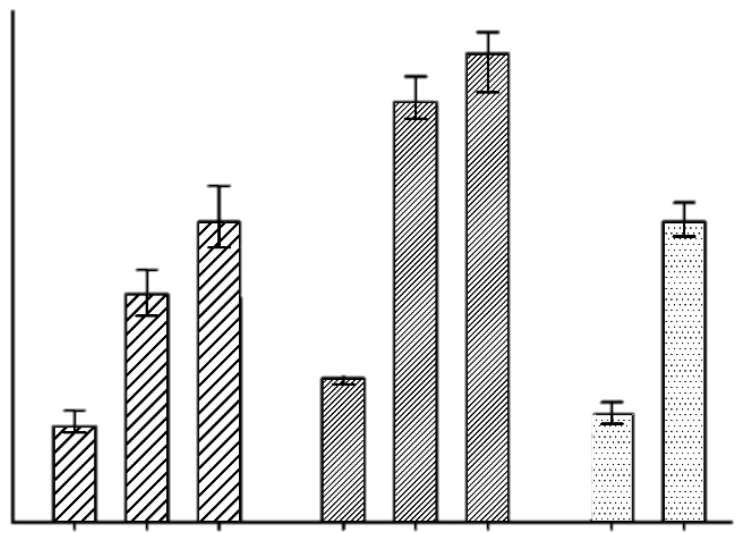

Figure 5: Cell counting results of blank, Col I and Col II groups.

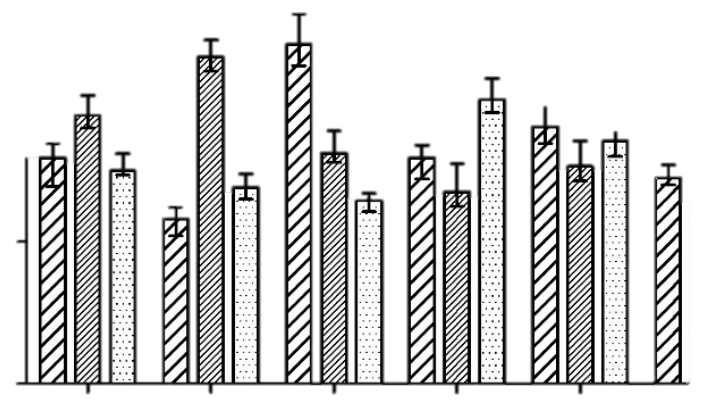

Figure 6: The relative content of different proteins expressed in blank, Col I and Col II groups.

the titanium alloys surface. The Si2p peak at $102.2 \mathrm{eV}$ belonged to $\mathrm{Si}-\mathrm{O}$ bonds which were formed between $\mathrm{Si}-\mathrm{OH}$ and $\mathrm{KH}-550$. These results indicated that $\mathrm{KH} 550$ was immobilized onto the titanium alloys surface and there was amidogen on the surface of the titanium alloys, which provided a basis for further collagen coupling.

Collagen coating is usually used to improve surface hydrophily and cell compatibility of titanium alloys. The influence of different collagen types coated on the titanium alloys to the cell compatibility and differentiation was different. In this research, Col I and Col II were coated on titanium alloys, respectively. The marker peptides and the contents of Col I and Col II were identified and quantified by HPLC-MS. The results showed that there were no significant differences between the coated amounts of Col I and Col II, and the collagen type had no effect on the coating amount to the titanium alloys. Thus, the collagen type may be the main factor affecting the cell proliferation and differentiation.

It was reported that collagen was suitable for cell adhesion and growth. For example, the Phe-Hyp-Gly sequence in collagen was the ligands for the integrin family receptors of cell surface. It could also promote cell attachment and proliferation by activating specific biological signals $[39,40]$. The cell attachment morphology and amount of the mouse pre-osteoblast cells were analyzed by SEM and nucleus counting. Compared with the blank group, the titanium alloys coated with collagen were more suitable for cell attachment
(Figure 3). The cell counting results showed that the number of cells in Col I and Col II group were higher than the blank group. And the blank group was $2.5 \times 105 / \mathrm{mL}$ on day 3 , which was much lower than the Col I $(3.9 \times 105 / \mathrm{mL})$ and Col II group $(2.9 \times 105 / \mathrm{mL})$. Not only the cell proliferation rate, but the spreading area, pseudopodia of the collagen group were also better than the blank group. The cell protein expression results of mouse pre-osteoblast cells were analyzed by HPLC-MS.

Six kinds of proteins were identified. It showed that mouse Col I and fibronectin were abundantly expressed in Col I group. Fibronectin binds to various proteins on the cell surface, participates in cell adhesion and osteoblast fibril synthesis, and regulates Col I deposition [41, 42]. The most abundant proteins in Col II group were osteopontin and prelamin-A/C. Osteopontin is expressed in a large amount during the cell mineralization phase, which can promote the deposition of hydroxyapatite [43]. Prelamin-A/C plays a role in osteogenesis and bone formation. Nidogen-2, the most aboundant protein in the blank group, was a kind of glycoproteins. And it can be involved in extracellular matrix interactions [44]. The results showed that cells cultured on Col I coating material mainly expressed proteins related to matrix synthesis, but cells cultured on Col II coating material mostly expressed proteins related to mineralization and calcium salt deposition. This indicated that collagen coating could improve the biocompatibility of the material, and different types of collagen could regulate cells to express different functional proteins.

\section{CONCLUSIONS}

The titanium alloys were modified by KH550 and coated with Col I and Col II, respectively. The coated amount of Col I and Col II on the titanium alloys surface were similar. Titanium alloys coated with collagen exhibited better state of cell adhesion and faster proliferation rate than the blank group. The cells cultured on Col I and Col II group expressed proteins associated with matrix synthesis and mineralization, calcium salt deposition, respectively. Collagen coating can improve the biocompatibility of titanium alloys, and different types of collagen can induce cell to express proteins with different functions.

\section{ACKNOWLEDGMENTS}

Science and Technology Program of Guangzhou, China, No. 201803010086; National K R \& D Program of China, No. 2018YFA0108200; National K R \& D Program of China, No. 2018YFC1106402.

\section{REFERENCES}

[1] Strite S and Morkoc H 1992 J. Vac. Sci. Technol. B 10 1237. DOI: https://doi.org/ $10.1063 / 1.1318235$

[2] Hsueh YH, Cheng CY, Chien HW, Xhh D, Cwh D, Chw A, Stc E and Sfo D 2020 J Alloy Compd 830 154490. DOI:10.1016/j.jallcom.2020.154490

[3] Koizumi H, Takeuchi Y, Imai H, Kawai T and Yoneyama T 2019 J Prosthodont Res 63266 - 70. DOI: https://doi.org/10.3390/nu12041031.

[4] Sharan J, Koul V, Dinda AK, Kharbanda OP, Lale SV, Duggal R, Mishra M, G Gupta and Singh MP 2018 Colloids Surf. B 161 1-9.

[5] Zhu XL, Chen J, Scheideler L, Reichl R and Geis-Gerstorfer J 2004 Biomaterials 254087 - 103. DOI: https://doi.org/10.1021/la981379u

[6] Variola F, Yi JH, Richert L, Wuest JD, Rosei F and Nanci A 2008 Biomaterials 29 1285 - 98. DOI:10.1007/978-0-387-48444-0 29.

[7] Sharan J, Lale S, Koul,V, Mishra M, Kharbandaet OP 2015 Trends Biomater. Artif. Organs 29176 - 87. DOI:10.1016/j.socec.2005.11.017 
[8] Morra M 2006 Eur. Cells Mater 12 1-15. DOI:doi:10.1016/j.dental.2005.06.008

[9] Kaur M and Singh K 2019 Mat Sci Eeg C-Mater 102844 - 62.

[10] Luo L, Jiang ZY, Wei DB and He HF 2014 Adv. Mat. Res. 887-888 1115 - 20.

[11] Tamura R, Oda D, Quaranta V, Plopper G, Lambert R, Glaser S and Jones JCR 1997 J. Periodont. Res. 32287 - 94. DOI10.1111/j.1600-0765.1997.tb00536.x

[12] Rapuano BE and MacDonald DE 2011 Colloids Surf. B Bio interfaces 8595 - 103

[13] Assis SL, Wolynec S and CostaI I 2006 Electrochim. Acta 511815 - 19

[14] Silverman BM, Wieghaus KA and Schwartz J 2005 Langmuir $21225-28$. DOI:10.1021/la0482271

[15] Jonge LD, Leeuwenburgh SG, Wolke JC and Jansen JA 2008 Pharm Res 252357 69. DOI: $10.1007 / \mathrm{s} 11095-008-9617-0$

[16] Aparicio C, Guillem-Marti J, Salvagni E, Marín-Pareja N and MP Ginebra 2014 Colloids Surf B Bio interfaces 122601 - 10. DOI: https://doi.org/10.1116/1.4878215.

[17] González M, Salvagni E, Rodríguez-Cabello JC, Rupérez E and Maneroet JM 2013 J Biomed Mater Res A 101A 819 - 26.

[18] Salvagni E, Berguig G, Engel E, Rodriguez-Cabello JC, Coullerez G, Textor M Planell JA, Gil FJ and Aparicio C 2014 Colloids Surf B 114225 - 33.

[19] Holmberg KV, Abdolhosseini M, Li Y, Chen X, Gorr SU and Aparicio C 2013 Acta Biomater 98224 - 31. DOI:10.1007/978-94-007-2592-8 4.

[20] Chen X, Sevilla P and Aparicio C 2013 Colloids Surf B 107189 - 97. DOI:10.1016/j.colsurfb.2013.02.005

[21] Wang KF, Zhou CC, Hong YL and Zhang X 2012 Interf Focus 2 259-77.

[22] Radin S and Ducheyne P1996 J. Biomed Mater Res 30273 - 79.

[23] Kazek-Kęsik A, Pietryga K, Basiaga M, Blacha-Grzechnik A, Dercz G, KalembaRec I, Pamua E and Simka W 2017 Surf Coat Tech 328 1-12.

[24] Chattopadhyay S and Raines R. 2014 Biopolymers 101821 - 33 DOI:10.1002/bip.22486.

[25] Ramshaw JM, Werkmeister JA and Dumsday GJ. 2014 Bioengineered 5227 - 33. DOI: 10.4161/bioe.28791. Epub 2014 Apr 9.

[26] Dong CJ and Lv YG. 2016 Polymers 842.

[27] Ferraro V, Gaillard-Martinie B, Sayd T, Chambon C, Anton M and Santé-Lhoutellieret V 2017 Int. J. Biol. Macromol 9755 - 66 . DOI:10.1016/j.ijbiomac.2016.12.068.
[28] Peng GZ, Li SN, Peng O, Li Y, Weng J, Jia Z, Kang J, Lei X, Zhang G and Gao Y 2017 J Biomater Appl 32 93-103. DOI: 10.1177/0885328217709607

[29] Pataridis S, Eckhardt E, Mikulíková K, Sedláková P and Mikík I 2009 Curr Anal Chem 5316 - 23. DOI:10.2174/157341109789077704

[30] Kuttappan S, Mathew D and Nair MB 2016 Int J Biol Macromol 931390 - 1401. DOI:10.1016/j.ijbiomac.2016.06.043

[31] Morra M, Cassinelli C, Cascardo G, Chanlan P, Fini M and Giardino R 2003 Biomaterials 24 4639-54. DOI:10.1016/S0142-9612(03)00360-0.

[32] Hofer A, Wolf C, Roehlecke C, Witt M, Kasper M, Funk RW and Schulze E 2001 Cells Tissues Organs $168178-87$.

[33] Becker D, Geissler U, Hempel U, Birebaum D and Scharnweber 2002 J. Biomed. Mater Res 59516 - 27. DOI:10.1002/jbm.1265

[34] Nagai M, Hayakawa T, Fukatsu A, Yamamoto M, Fukumoto M, Nagahama F, Mishima H, Yoshinari M, Nemoto K and Kato T 2002 Dent Mater J 12250 - 60.

[35] Kado T, Hidaka T, Aita H, Endo K and Y Furuichi 2012 Appl Surf Sci 262240 - 47. DOI:10.1016/j.apsusc.2012.07.091

[36] Antonio G, Claudia B, Massimo C, Snadra M and Greco F 2003 J Mater Ssi-Mater M 14713 - 16.

[37] Buma P, Pieper JS, Tienen T and Susante V 2003 Biomaterials 243255 - 63. DOI: https://doi.org/10.1016/S0142-9612(03)00143-1

[38] Nehrer S, Breinan HA, Ramappa A. Young G, Shortkroff S, Louie LK, Sledge CB, Yannas IV and Spector M 1997 Biomaterials 18769 - 76. DOI:10.1002/(SICI)10974636(199722)38:2<95::AID-JBM3>3.0.CO;2-B

[39] Gigante A, Bevilacqua C, Cappella M, Manzotti S and Greco F 2003 J Mater Sci-Mater M 14 713-16.

[40] Orgel JP, San Antonio JD and Antipova O. 2011 Connect Tissue Res 52 2-17.

[41] Mayne R, Rich PR, Gurusiddappa S, Owens JR, Hook M, Hook MA, Xu YF and Keene JD 2000 J Biol Chem $27538981-89$.

[42] Kachroo U and Vinod E 2020 The Knee 27755 - 9.

[43] Wang K, Wu F, Seo BR, Fischbach C, Chen W, Hsu L and Gourdon D 2017 Matrix Biol 6186 -95. DOI: https://doi.org/10.1016/j.matbio.2016.08.001.

[44] Boskey AL, Christensen B, Taleb H and Srensen ES 2012 Biochem Biophys Res Commun 419333 - 8. DOI:10.1016/j.bbrc.2012.02.024 